\title{
Effects of verapamil on haemodynamic function and myocardial metabolism in patients with hypertrophic cardiomyopathy
}

\author{
P T WILMSHURST, D S THOMPSON, S M JUUL, B S JENKINS, \\ $M$ M WEBB-PEPLOE
}

From the Cardiac Department, St Thomas' Hospital, London

SUMMARY The effect of $20 \mathrm{mg}$ dose of intravenous verapamil was studied over a range of heart rates in 12 patients with hypertrophic cardiomyopathy. Six patients had an appreciable left ventricular outflow tract gradient and six did not. The drug reduced myocardial oxygen consumption in proportion to a reduction in the development of left ventricular pressure. The negative inotropic effect of verapamil was counteracted by the drug's non-specific vasodilator activity, so that cardiac index was unaltered at any heart rate and as a result myocardial efficiency was unaffected by the drug. Verapamil did not consistently alter myocardial metabolism. Some patients showed improvement in anaerobic myocardial metabolism after verapamil but an equal number showed impairment of lactate metabolism. It was not possible to predict from clinical features, echocardiographic findings, or haemodynamic variables measured before administration of verapamil which patients would demonstrate haemodynamic or metabolic improvement after the drug.

In this short term study no mechanism was demonstrated by which patients with hypertrophic cardiomyopathy might obtain a consistent improvement from treatment with verapamil.

Verapamil has been advocated for the treatment of patients with hypertrophic cardiomyopathy ${ }^{12}$ although the rationale for such treatment is unclear. The animal models of cardiomyopathy on which this treatment was proposed have no proven relation with human hypertrophic cardiomyopathy. ${ }^{2}$ Furthermore, the early promise ${ }^{34}$ that verapamil treatment would reverse left ventricular hypertrophy in patients with hypertrophic cardiomyopathy is now disputed. ${ }^{5}$ Nevertheless, verapamil treatment is claimed to improve symptoms and exercise tolerance $^{56}$ despite its failure consistently to improve systolic $^{6}$ or diastolic left ventricular function ${ }^{7}$ and an absence of information about the metabolic effects of the drug in this disease.

We have investigated the metabolic and haemodynamic changes induced by verapamil over a range of heart rates to see whether we could find a

Requests for reprints to Dr P T Wilmshurst, Cardiac Department, St Thomas' Hospital, London SE1 7EH.

Accepted for publication 8 July 1986 consistent beneficial action of the drug. We also compared the response to the drug in a group of patients who had left ventricular outflow tract gradients with the response in a group who did not, to determine whether any beneficial effect of the drug is dependent on the presence of an outflow gradient.

\section{Patients and methods}

We studied 12 symptomatic patients with the physical signs and echocardiographic features of hypertrophic cardiomyopathy. They were all normotensive and none had valvar heart disease or coronary artery disease.

Two groups of six were defined during preliminary diagnostic cardiac catheterisation. Group $A$, the non-obstructed group, consisted of four patients in whom no left ventricular intracavity gradient was present at rest, on post-extrasystolic beats, or during amyl nitrite administration and two patients in whom a gradient of $<20 \mathrm{~mm} \mathrm{Hg}$ could be provoked. Group B, those with obstruction consisted of four patients with a resting left ventricular 
Table 1 Clinical details and echocardiographic features of the patients with hypertrophic cardiomyopathy

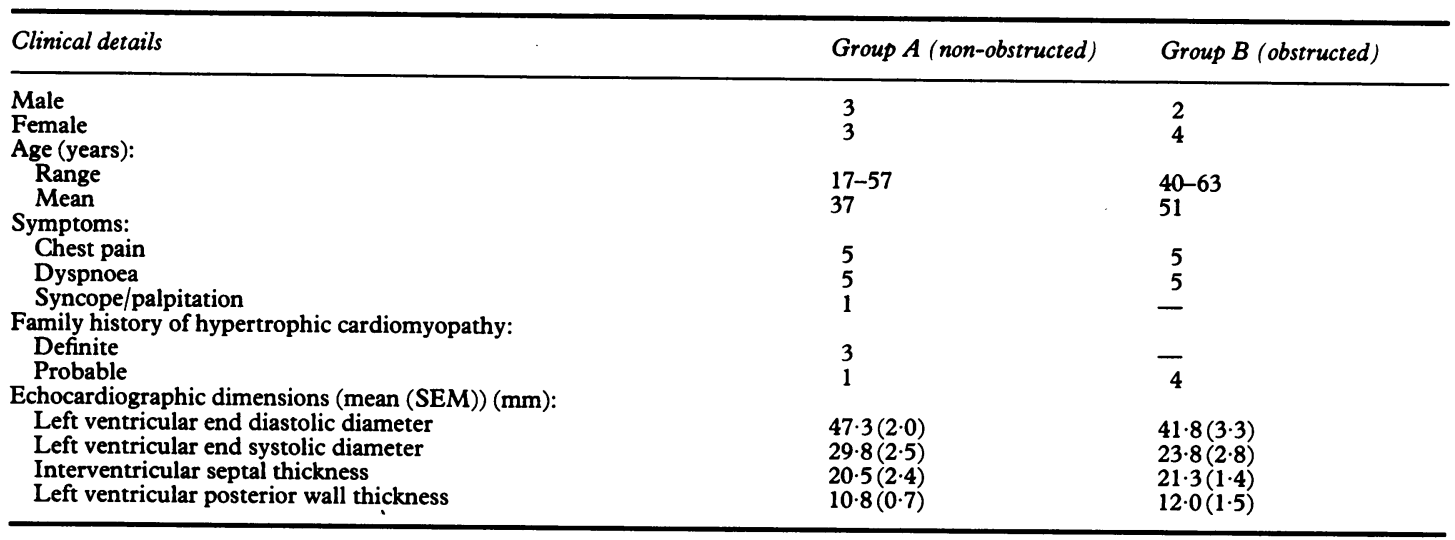

intracavity gradient of $>35 \mathrm{~mm} \mathrm{Hg}$ (maximum $164 \mathrm{~mm} \mathrm{Hg}$ ) and two patients with resting gradients of $<20 \mathrm{~mm} \mathrm{Hg}$ which rose to greater than $50 \mathrm{~mm} \mathrm{Hg}$ after amyl nitrite. Data from the two groups were analysed separately and in combination. Table 1 gives the clinical details of patients.

Each patient gave informed written consent to the study which had the approval of the hospital ethics committee. Before the study four patients receiving propranolol and two who were taking verapamil had these drugs stopped for at least $\mathbf{4 8}$ hours. Diuretics were continued in the four group $A$ and three group $B$ patients receiving them. One patient with obstruction (group B) received carbimazole and another took thyroxine. These drugs were continued and the patients were euthyroid at the time of the investigation.

The study was performed after an overnight fast. Diazepam $10 \mathrm{mg}$ and atropine $0.6 \mathrm{mg}$ were given intramuscularly as premedication one hour before cardiac catheterisation. At the same time intravenous heparin ( 45 units $/ \mathrm{kg}$ ) was given to minimise the effect of a subsequent dose of heparin on free fatty acid concentrations. ${ }^{8}$ Routine cardiac pressures were measured and coronary arteriography was performed via catheters inserted under local anaesthesia with lignocaine. A second dose of heparin was given immediately after arterial catheterisation. The left ventricular outflow gradient was measured by catheters positioned in the left ventricular body transseptally via the interatrial septum and retrogradely across the aortic valve. An intracavity gradient was provoked as described above.

After we confirmed consent to proceed with the research study, we positioned a number 8 French gauge catheter with a micromanometer tip (Gaeltec or Millar) transseptally in the left ventricular body by means of the long sheath technique. It was used to record high fidelity pressure and for left ventricu- lar cineangiography (with $76 \%$ Urografin). Aortic pressure was measured with a fluid filled catheter, cardiac output by dye dilution, and coronary sinus flow by thermodilution.

Pressures were measured with reference to the sternal angle. Pressure, micromanometer, and thermistor signals were displayed on a Cambridge 12 channel recorder, stored on magnetic tape, and processed by on line computer. Contractility indices including the maximum rate of rise of left ventricular pressure ( $\left.\mathrm{dP} / \mathrm{dt}_{\max }\right), \mathrm{dP} / \mathrm{dt}_{\max }$ divided by developed pressure $\left(\mathrm{dP} / \mathrm{dt}_{\max } \div \mathrm{P}\right)$, and the product of the series elastic stiffness constant and the velocity of contractile shortening at zero load $\left(\mathrm{KV}_{\text {max }}\right)$ were derived from the micromanometer signal.

More than 30 minutes elapsed between arteriography and subsequent measurements. Pressures and flows were measured and arterial and coronary sinus blood were sampled simultaneously for measurement of metabolite contents at the basal heart rate (sinus rhythm) and during coronary sinus pacing. Subjects were paced where possible at 25 , 50 , and 75 beats/minute above their pre-verapamil basal rate $(+25,+50,+75)$. Left ventricular cineangiography (right anterior oblique projection) was then performed during pacing at 10 beats/minute above the basal heart rate. Twenty minutes later $20 \mathrm{mg}$ of verapamil was infused intravenously over two minutes. Seven minutes after the verapamil infusion haemodynamic measurements and metabolite sampling were repeated at the intrinsic heart rate and then, where possible, during pacing at identical heart rates to those used earlier. A second left ventricular cineangiogram was performed at a paced rate identical to that used for the first angiogram. Post-verapamil measurements and angiography were completed within $\mathbf{4 0}$ minutes of drug administration in each case.

The oxygen content and concentrations of lactate, 
pyruvate, hydroxybutyrate, acetoacetate, glycerol, and free fatty acid in arterial and coronary sinus blood were determined. ${ }^{8}$ Derived haemodynamic and metabolic variables were calculated by standard formulas. Left ventricular volumes (Dodge method) were calculated by planimetry.

We used the paired $t$ test, the $t$ test for small samples, and linear regression as appropriate for statistical analysis. Values are expressed as mean (1 SEM). A value of $p<0.05$ was regarded as statistically significant.

\section{Results}

HAEMODYNAMIC EFFECTS OF VERAPAMIL In the basal state all patients were in sinus rhythm (rate 74.6 (4.8) beats/minute). Five patients could be paced to +75 , another five to +50 , and two patients could be paced only to +25 .

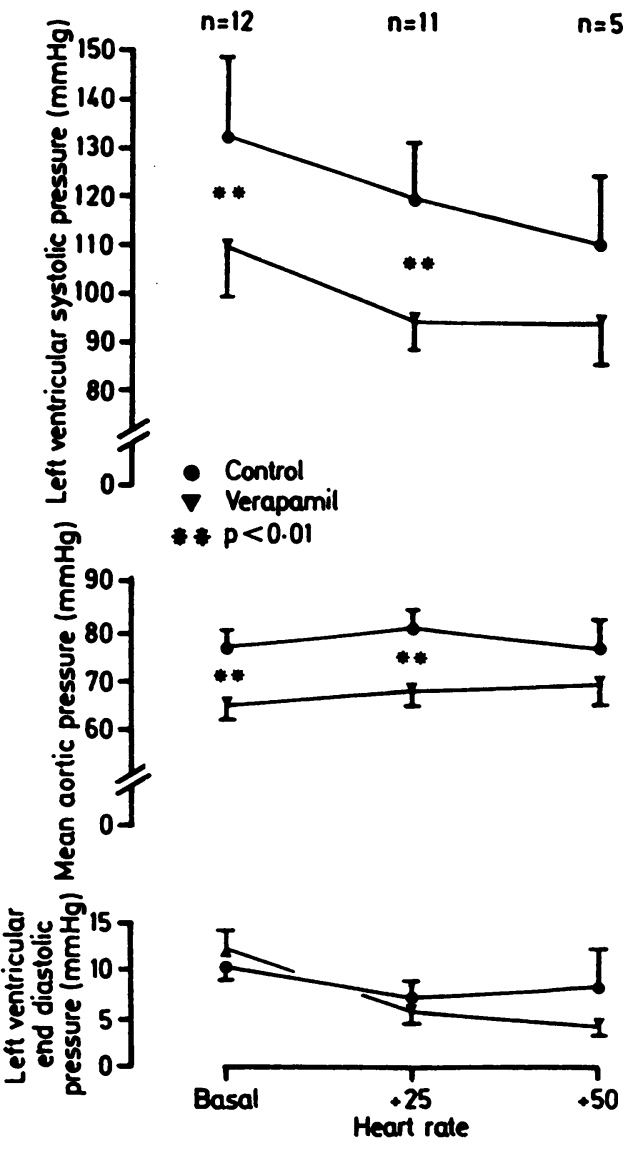

Fig 1 Effect of verapamil on left heart pressures (mean (SEM)) in hypertrophic cardiomyopathy.
After intravenous verapamil complete heart block developed in one patient and one had a nodal bradycardia. Both arrhythmias resolved spontaneously within the seven minute period allowed before measurements were made. The post-verapamil basal rate $(70.2(3.6)$ beats/minute) was not significantly different from the pre-verapamil basal rate. After verapamil only two patients could be paced to +75 and another three to +50 . One patient could not be paced at all after verapamil. The highest average paced rate pre-verapamil was $131 \cdot 5(4 \cdot 6)$ beats/ minute and post-verapamil it was $111.2(6.5)$ beats/minute $(p<0.01)$.

Figures 1-6 show the haemodynamic effects of verapamil at the heart rates chosen. Only patients who could be paced at the specified heart rates preverapamil and post-verapamil are included in the analysis. Data from the two patients who could be paced to +75 both before and after verapamil are

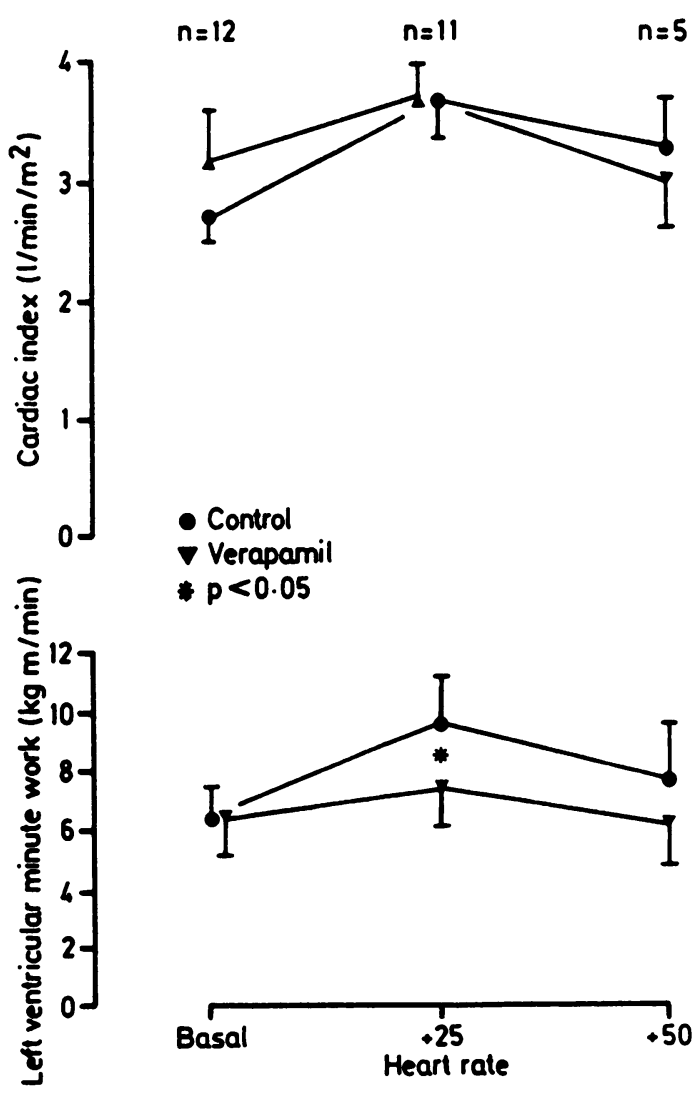

Fig 2 Effect of verapamil on cardiac index and left ventricular minute work (mean (SEM)) in hypertrophic cardiomyopathy. 

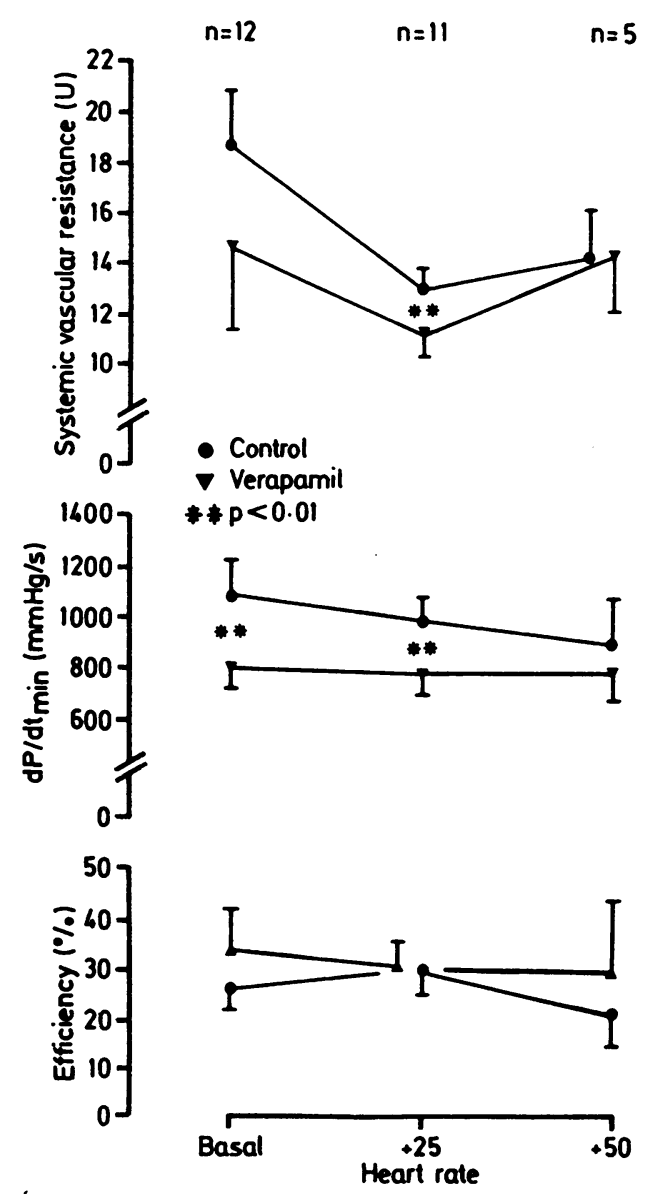

Fig 3 Effect of verapamil on systemic vascular resistance, $d P / d t_{\min }$ and efficiency (mean $(S E M)$ ) in hypertrophic cardiomyopathy.

not suitable for statistical analysis. These data, however, resembled the effects in the larger group at +50 .

Verapamil did not significantly alter the peak left ventricular outflow tract gradient at any heart rate in the group of 12 patients or in the subgroup with obstruction (group B), although the gradient tended to fall at each heart rate after verapamil. In group B the basal gradient was $61.7(27.5) \mathrm{mm} \mathrm{Hg}$ and after verapamil the gradient was $47 \cdot 2(17 \cdot 7) \mathrm{mm} \mathrm{Hg}$.

Verapamil did not alter the cardiac index significantly at any heart rate (fig 2), so that the small reduction in left ventricular minute work after verapamil at $+25(p<0.05)$ is the result of reduced pressure development.

The reduction in total systemic vascular resistance was statistically significant with pacing at +25 but just failed to achieve significance at the

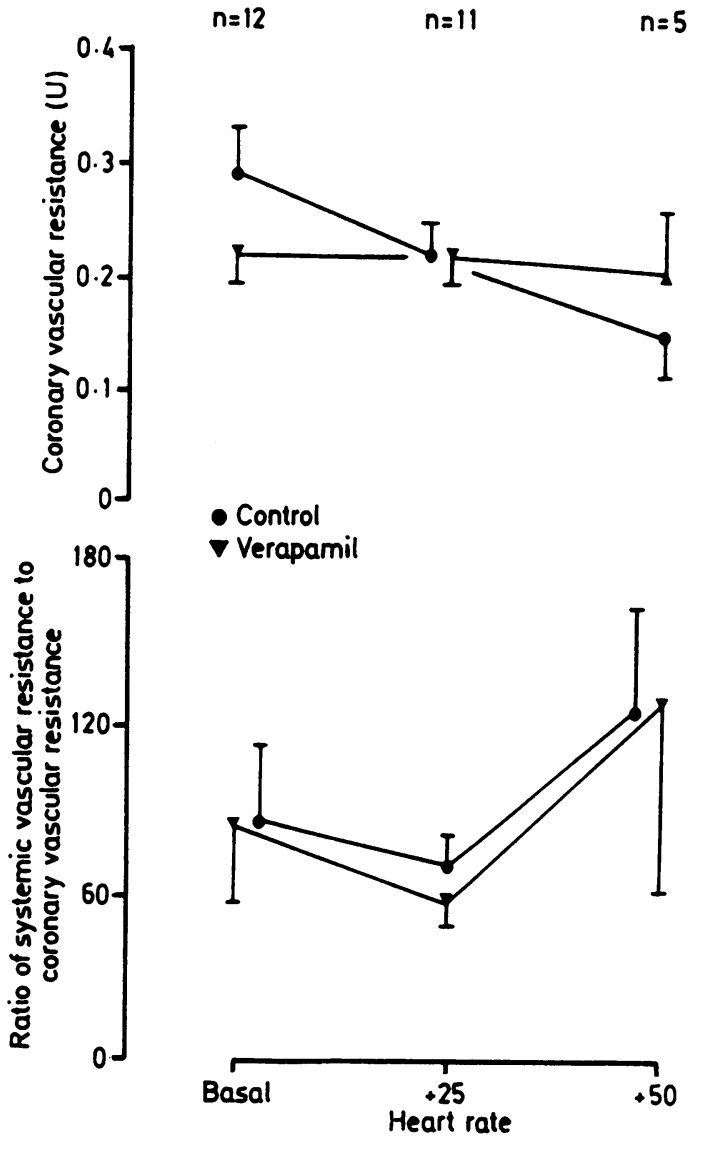

Fig 4 Effect of verapamil on coronary vascular resistance and the ratio of systemic vascular resistance to coronary vascular resistance (mean (SEM)) in hypertrophic cardiomyopathy.

basal rate $(0.05<p<0.1)$ (fig 3$)$. The reduction in coronary vascular resistance after verapamil also just failed to achieve significance at the basal rate $(0.05$ $<\mathrm{p}<0 \cdot 1)$ (fig 4). Verapamil did not affect systemic or coronary vascular resistances at higher rates. It was notable that with increasing heart rates coronary vascular resistance fell progressively in 11 of the 12 patients before verapamil but after the drug it was not altered by pacing.

In one patient pacing could not be re-established after verapamil and no second left ventricular cineangiogram was performed. Figure 7 shows the angiographically derived data for the remaining eleven patients.

METABOLIC EFFECTS OF VERAPAMIL

Myocardial extractions, extraction ratios, and oxygen extraction ratios of lactate (table 2) and, to a 

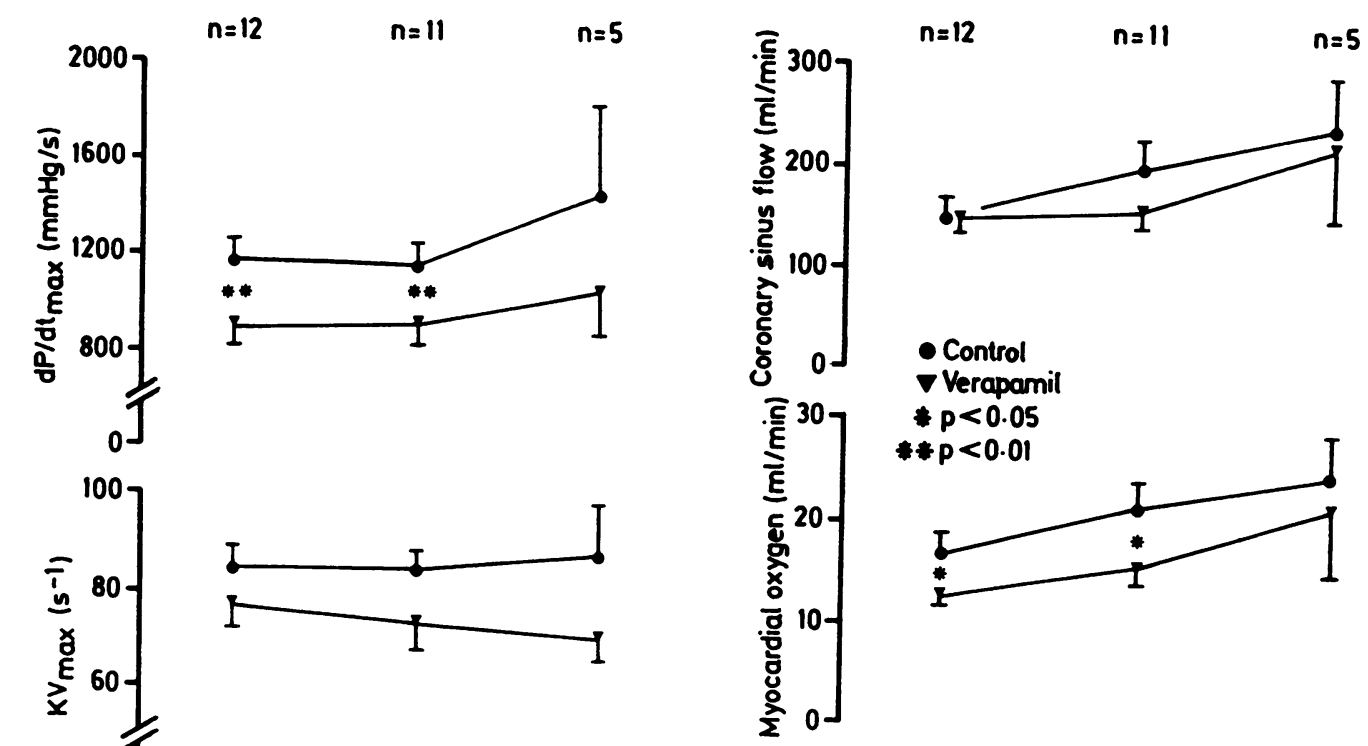

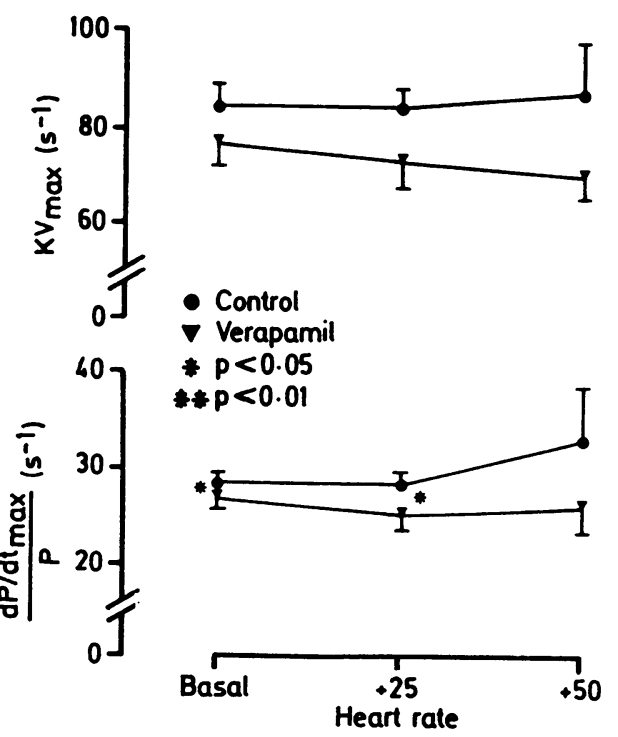

Fig 5 Effect of verapamil on indices of contractility in hypertrophic cardiomyopathy (mean (SEM)).

lesser extent, pyruvate (table 3 ) were reduced at higher heart rates. Verapamil did not affect the overall myocardial metabolism of these substrates in the group of patients studied although it had clinically important effects in some individuals.

In two patients with abnormal lactate extraction $(0-10 \%)$ pre-verapamil, normal lactate extraction developed at identical heart rates after the drug. A further patient who had been a lactate producer $(-16 \%)$ at high heart rates pre-verapamil could not be paced rapidly after the drug and thus had normal lactate extraction $(41 \%)$ at the highest rate achieved after the drug. Three patients had normal lactate extraction pre-verapamil that became impaired after the drug. One developed abnormal lactate extraction at an identical heart rate after verapamil and two became lactate producers at lower rates.

In the remaining six patients verapamil had no major effect on lactate metabolism. Five patients had 

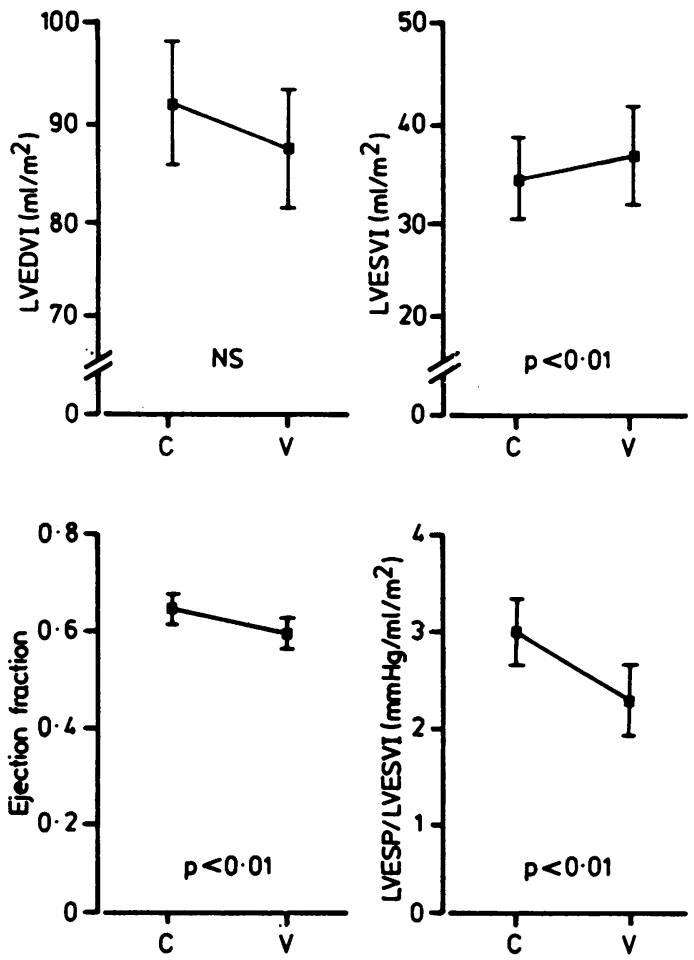

Fig 7 Haemodynamic effects (mean (SEM)) of verapamil in eleven patients with hypertrophic cardiomyopathy at constant paced heart rate. $C$, control; $V$, verapamil; $L V E D V I$, left ventricular end diastolic volume index; LVESVI, left ventricular end systolic volume index.

There was no clear relation between control haemodynamic variables and changes in myocardial metabolism after verapamil-no subgroup showing a metabolic improvement after the drug could be identified from control values for haemodynamic variables. The alteration in myocardial oxygen con- sumption after verapamil was, however, directly related to the change in left ventricular systolic pressure (fig 8) but was not related to changes in left ventricular filling pressure, cardiac index, systemic vascular resistance, or contractility indices. In group B there was a suggestion that changes in myocardial oxygen consumption were directly related to alterations in outflow gradient $(0.05<\mathrm{p}<0.1)$.

\section{COMPARISON OF GROUPS A AND B}

By definition the left ventricular outflow gradient was higher in group B patients (with obstruction) than in group A. This was true at all heart rates, both before and after verapamil. Consequently the left ventricular peak systolic pressure was higher in group B than in group A, so that aortic pressures in the two groups did not differ. After verapamil, mean aortic pressure tended to fall less in group $A$ than in group B at each heart rate (at basal heart rate, 9.8 (3.0) vs $15.2(3.8) \mathrm{mm} \mathrm{Hg}$; at $+25,7.3$ (2.2) vs 20.8 $(5.0) \mathrm{mm} \mathrm{Hg}$ ); however, these differences were only significant with pacing at +25 .

Although basal heart rates were similar in the two groups, it was possible to pace group A to higher rates than group B after verapamil. Thus four patients in group A but only one in group B could be paced to +50 and only group $A$ patients could be paced to +75 after verapamil.

Normalised left ventricular end diastolic volume was significantly greater in group A than in group B both before $\left(104.8(5.9)\right.$ vs $77.2(8.0) \mathrm{ml} / \mathrm{m}^{-2}$ ) and after verapamil (99.6 (7.6) vs $\left.73.2(3.9) \mathrm{ml} / \mathrm{m}^{-2}\right)$ but left ventricular end systolic volume indices and ejection fractions were not significantly different. At comparable heart rates in the control state myocardial oxygen consumption tended to be higher in group A than in group B although not significantly so. Myocardial oxygen consumption fell after verapamil in each group but the change was greater in group B. Thus after verapamil the differences in

Table 2 Lactate metabolism in patients with hypertrophic cardiomyopathy (mean (SEM))

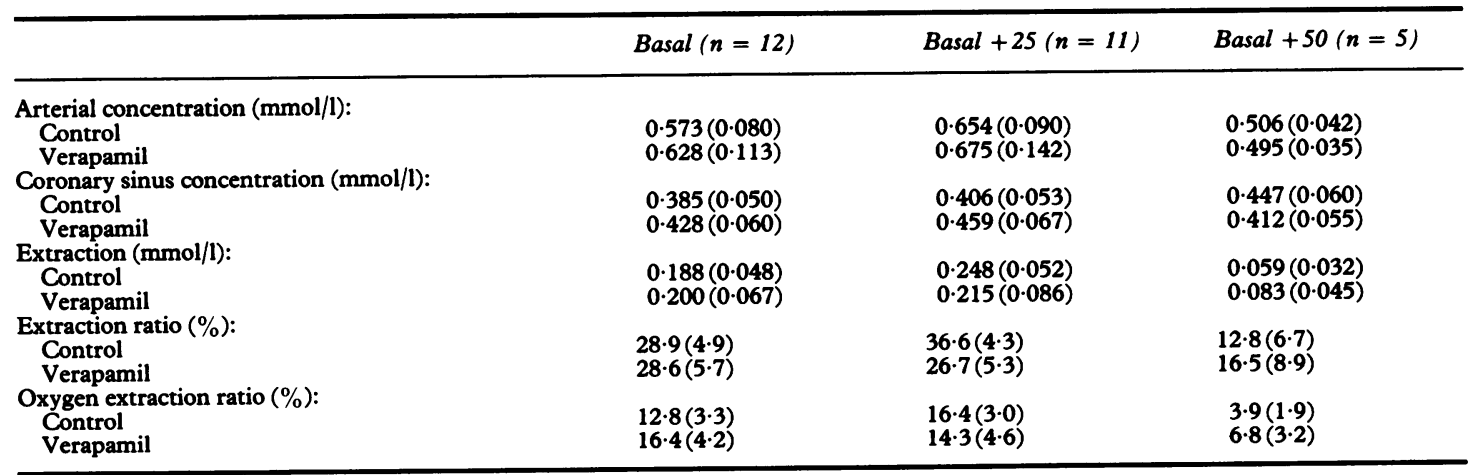


Table 3 Pyruvate metabolism in patients with hypertrophic cardiomyopathy (mean (SEM))

\begin{tabular}{|c|c|c|c|}
\hline & Basal $(n=12)$ & Basal $+25(n=11)$ & Basal $+50(n=5)$ \\
\hline \multicolumn{4}{|c|}{ Arterial concentration (mmol/1): } \\
\hline $\begin{array}{l}\text { Control } \\
\text { Verapamil }\end{array}$ & $\begin{array}{l}0.060(0.010) \\
0.060(0.013)\end{array}$ & $\begin{array}{l}0.060(0.012) \\
0.063(0.014)\end{array}$ & $\begin{array}{l}0.048(0.004) \\
0.053(0.005)\end{array}$ \\
\hline \multicolumn{4}{|c|}{ Coronary sinus concentration ( $\mathrm{mmol} / \mathrm{l})$ : } \\
\hline $\begin{array}{l}\text { Control } \\
\text { Verapamil }\end{array}$ & $\begin{array}{l}0.039(0.004) \\
0.038(0.006)\end{array}$ & $\begin{array}{l}0.037(0.004) \\
0.040(0.004)\end{array}$ & $\begin{array}{l}0.039(0.005) \\
0.043(0.005)\end{array}$ \\
\hline \multicolumn{4}{|c|}{ Extraction (mmol/1): } \\
\hline $\begin{array}{l}\text { Control } \\
\text { Verapamil }\end{array}$ & $\begin{array}{l}0.021(0.009) \\
0.021(0.010)\end{array}$ & $\begin{array}{l}0.023(0.009) \\
0.024(0.011)\end{array}$ & $\begin{array}{l}0.008(0.004) \\
0.010(0.005)\end{array}$ \\
\hline \multicolumn{4}{|c|}{ Extraction ratio (\%): } \\
\hline $\begin{array}{l}\text { Control } \\
\text { Verapamil }\end{array}$ & $\begin{array}{l}23.6(10.4) \\
23.9(11.2)\end{array}$ & $\begin{array}{l}27 \cdot 7(10 \cdot 0) \\
24.9(9 \cdot 1)\end{array}$ & $\begin{array}{l}17 \cdot 5(8 \cdot 0) \\
18 \cdot 2(8 \cdot 3)\end{array}$ \\
\hline \multicolumn{4}{|c|}{ Oxygen extraction ratio $(\%)$ : } \\
\hline $\begin{array}{l}\text { Control } \\
\text { Verapamil }\end{array}$ & $\begin{array}{l}1.3(0.5) \\
1.7(0.6)\end{array}$ & $\begin{array}{l}1.3(0.4) \\
1.3(0.5)\end{array}$ & $\begin{array}{l}0.6(0.2) \\
0.7(0.3)\end{array}$ \\
\hline
\end{tabular}

Table 4 Hydroxybutyrate metabolism in patients with hypertrophic cardiomyopathy (mean (SEM))

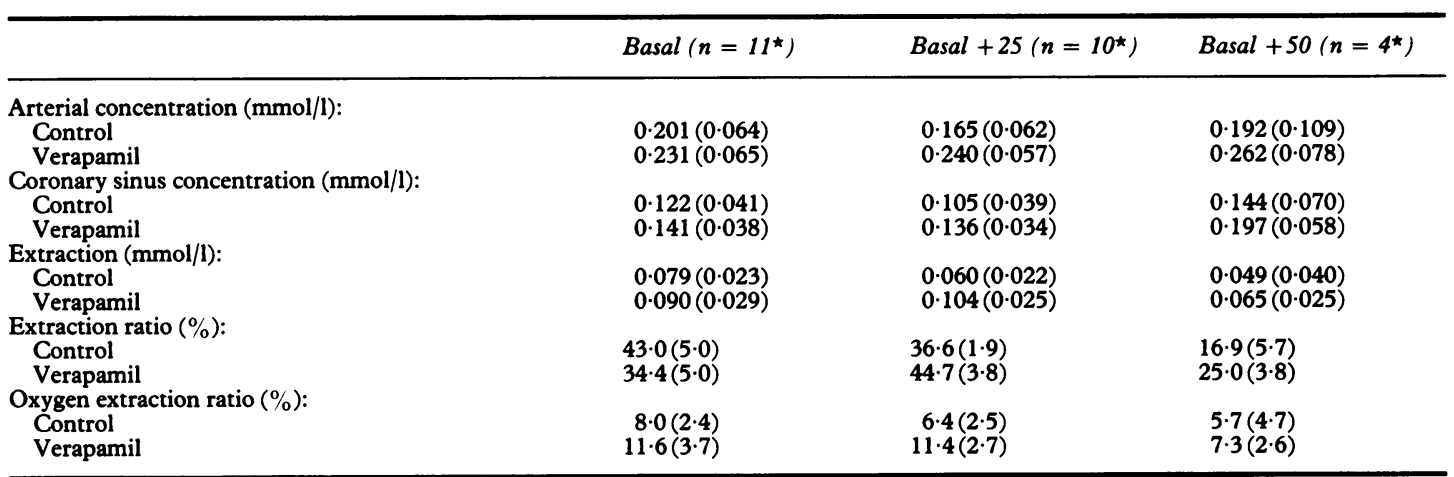

^The blood samples from one patient for estimation of hyroxybutyrate concentrations were accidentally destroyed.

Table 5 Acetoacetate metabolism in patients with hypertrophic cardiomyopathy (mean (SEM))

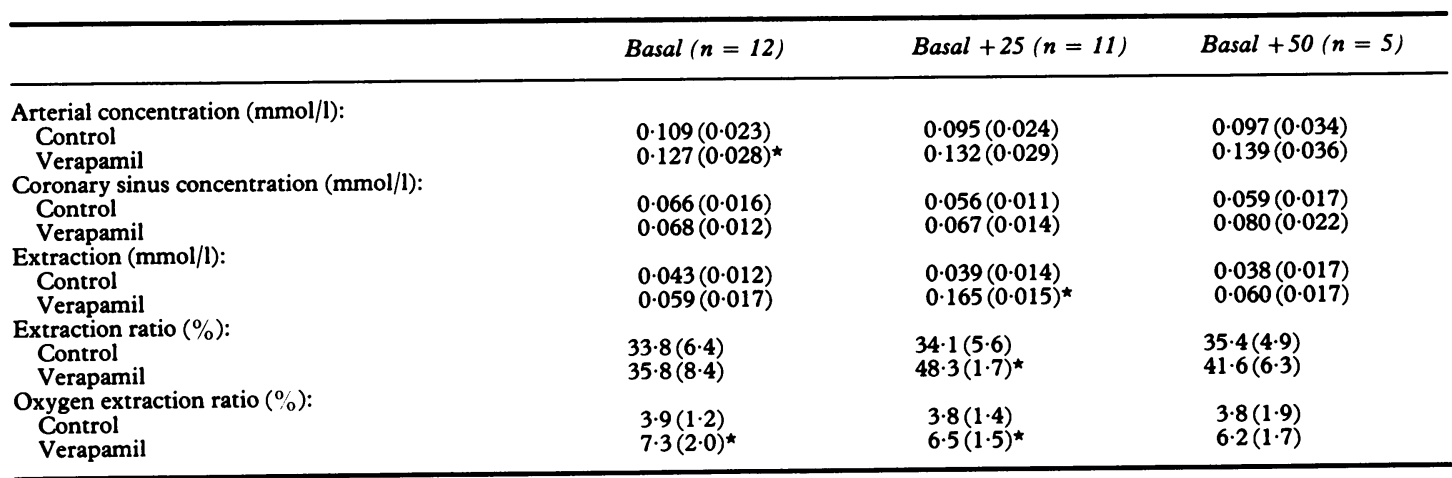

$\star_{\mathrm{p}}<0.05$. 
Table 6 Glycerol metabolism in patients with hypertrophic cardiomyopathy (mean (SEM))

\begin{tabular}{|c|c|c|c|}
\hline & Basal $(n=12)$ & Basal $+25(n=11)$ & Basal $+50(n=5)$ \\
\hline \multicolumn{4}{|c|}{ Arterial concentration ( $\mathrm{mmol} / \mathrm{l})$ : } \\
\hline $\begin{array}{l}\text { Control } \\
\text { Verapamil }\end{array}$ & $\begin{array}{l}0.073(0.017) \\
0.074(0.014)\end{array}$ & $0.058(0.011)$ & $0.053(0.017)$ \\
\hline \multicolumn{4}{|c|}{ Coronary sinus concentration ( $\mathrm{mmol} / \mathrm{l})$ : } \\
\hline $\begin{array}{l}\text { Control } \\
\text { Verapamil }\end{array}$ & $0.065(0.017)$ & $0.045(0.008)$ & $0.043(0.013)$ \\
\hline \multicolumn{4}{|c|}{ Extraction (mmol/l): } \\
\hline $\begin{array}{l}\text { Control } \\
\text { Verapamil }\end{array}$ & $0.009(0.005)$ & $0.013(0.005)$ & $0.010(0.009)$ \\
\hline \multicolumn{3}{|c|}{ Extraction ratio (\%): } & $0.009(0.013)$ \\
\hline Control & $14 \cdot 0(8 \cdot 2)$ & $18 \cdot 4(9 \cdot 2)$ & $9 \cdot 7(12 \cdot 3)$ \\
\hline $\begin{array}{l}\text { Verapamil } \\
\text { Oxygen extra }\end{array}$ & $1 \cdot 2(13 \cdot 1)$ & $8 \cdot 3(8 \cdot 6)$ & $4 \cdot 1(19.9)$ \\
\hline \multicolumn{4}{|c|}{ Oxygen extraction ratio (\%): } \\
\hline $\begin{array}{l}\text { Control } \\
\text { Verapamil }\end{array}$ & $\begin{array}{l}1.0(0.4) \\
1.5(0.6)\end{array}$ & $\begin{array}{l}1.2(0.4) \\
1.3(0.6)\end{array}$ & $1.0(0 \cdot 8)$ \\
\hline
\end{tabular}

Table 7 Free fatty acid metabolism in patients with hypertrophic cardiomyopathy (mean (SEM))

\begin{tabular}{|c|c|c|c|}
\hline & Basal $(n=12)$ & Basal $+25(n=11)$ & Basal $+50(n=5)$ \\
\hline \multicolumn{4}{|c|}{ Arterial concentration (mmol/l): } \\
\hline $\begin{array}{l}\text { Control } \\
\text { Verapamil }\end{array}$ & $\begin{array}{l}0.64(0.07) \\
0.67(0.07)\end{array}$ & $\begin{array}{l}0.63(0.09) \\
0.76(0.08)\end{array}$ & $\begin{array}{l}0.55(0.09) \\
0.63(0.13)\end{array}$ \\
\hline \multicolumn{4}{|c|}{ Coronary sinus concentration $(\mathrm{mmol} / \mathrm{l})$ : } \\
\hline $\begin{array}{c}\text { Verapamil } \\
\text { Extraction (m }\end{array}$ & $\begin{array}{l}0.53(0.08) \\
0.56(0.08)\end{array}$ & $\begin{array}{l}0.49(0.08) \\
0.66(0.07)\end{array}$ & $\begin{array}{l}0.49(0.05) \\
0.54(0.11)\end{array}$ \\
\hline $\begin{array}{l}\text { Control } \\
\text { Verapamil }\end{array}$ & $0.11(0.02)$ & $0.14(0.03)$ & $0.06(0.04)$ \\
\hline Extraction ratio (\%): & $0 \cdot 10(0.03)$ & $0 \cdot 10(0.05)$ & $0.09(0.03)$ \\
\hline $\begin{array}{l}\text { Control } \\
\text { Verapamil }\end{array}$ & $\begin{array}{l}19 \cdot 6(4 \cdot 7) \\
17 \cdot 6(4 \cdot 4)\end{array}$ & $\begin{array}{l}21 \cdot 8(4 \cdot 9) \\
13 \cdot 5(5 \cdot 2)\end{array}$ & $\begin{array}{c}8 \cdot 6(4 \cdot 4) \\
12 \cdot 8(3 \cdot 6)^{\star}\end{array}$ \\
\hline \multicolumn{4}{|c|}{ Oxygen extraction ratio (\%): } \\
\hline $\begin{array}{l}\text { Control } \\
\text { Verapamil }\end{array}$ & $77 \cdot 4(14 \cdot 7)$ & $\begin{array}{l}74.5(17 \cdot 3) \\
63.0(21 \cdot 0)\end{array}$ & $\begin{array}{l}34 \cdot 3(20 \cdot 1) \\
50 \cdot 8(18 \cdot 6)\end{array}$ \\
\hline
\end{tabular}

${ }^{\star} \mathrm{p}<0.05$

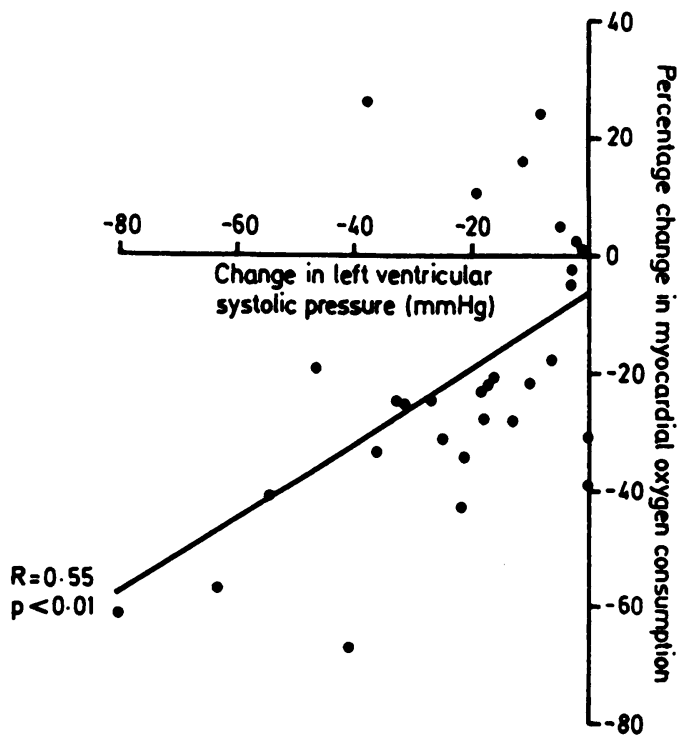

Fig 8 Relation between changes in left ventricular systolic pressure and myocardial oxygen consumption. myocardial oxygen consumption between the groups became statistically significant (at basal rate, A $14.1(1.0)$ vs B $10.9(1.0) \mathrm{ml} / \mathrm{min}$; at +25 , A $18.9(1.1)$ vs B $11.6(1.2) \mathrm{ml} / \mathrm{min} ; \mathrm{p}<0.05)$.

Verapamil produced no apparent difference in myocardial metabolism, as judged from metabolite concentrations, extractions, or extraction ratios, in the two subgroups at basal heart rate. When paced at +25 some differences were seen between the subgroups. Compared with the pre-verapamil state each patient in group B showed a reduction in lactate extraction $(0.081(0.030)$ vs $0.236(0.068) \mathrm{mmol} / \mathrm{l}, \mathrm{p}$ $<0.05)$, extraction ratio $(19.3(7.3) v 37.7(7.9) \%$, p $<0.02)$, and oxygen extraction ratio $(5.9(1.9)$ vs $15.6(4.4) \%, p<0.05)$ but these were unchanged in the patients in group $A$.

We found no other haemodynamic or metabolic differences between the groups.

\section{Discussion}

We evaluated the effects of verapamil independently of the drug's heart rate effect by using fixed pacing rates. By studying the effect of the drug over a range 
of heart rates it was possible to seek consistent changes in individual patients and the groups. Pacing also enabled us to apply stress and thus alter myocardial work and oxygen consumption, which are thought to be important determinants of symptoms and prognosis in hypertrophic cardiomyopathy.

The effects of intravenous verapamil on simple basal resting haemodynamics (heart rate, cardiac index, and left ventricular and aortic pressures) in this study accorded well with previous studies. ${ }^{2} 69$ In addition, the present study suggests that these effects of intravenous verapamil on cardiac index and pressures also apply at higher heart rates. It also confirms that although intravenous verapamil has little effect on left ventricular end diastolic volume, ${ }^{210}$ left ventricular end systolic volume increases and ejection fraction decreases. ${ }^{10}$

As in a previous study ${ }^{10}$ we observed a reduction in the left ventricular end systolic pressure to volume ratio, suggesting a reduction in left ventricular contractility because heart rate remained constant. These observations accord with our measurements of isovolumic contractile indices which indicate that verapamil has negative inotropic properties at all rates.

This reduction in left ventricular contractility explains the observations that outflow gradient usually fell despite afterload reduction. It would also explain the absence of a reduction in left ventricular end diastolic pressure and volume despite verapamil induced systemic vasodilatation.

Our observations that left ventricular end diastolic pressure and volume were unaltered by verapamil are counter to the finding by other groups of improved diastolic function in some but not all patients after acute intravenous verapamil ${ }^{10}$ and during long term oral drug treatment. ${ }^{6}$ The suggestion that verapamil may improve diastolic function is central to the argument by these groups that verapamil is a valuable drug for treating hypertrophic cardiomyopathy. Our contradictory findings could partly be accounted for by our measuring volume during coronary sinus pacing, with a consequent alteration of the timing of the atrial contribution to ventricular filling. Other data, however, suggest that any beneficial action of verapamil on ventricular filling is independent of this atrial contribution, ${ }^{11}$ so that the protocol used should not have masked a beneficial action of verapamil on filling; we have previously failed to demonstrate a beneficial effect of the drug on ventricular isovolumic relaxation in this disease. ${ }^{7}$

At all rates the ratio of coronary to systemic vascular resistance was unaltered by verapamil. This suggests a non-specific vasodilating effect without a specific coronary dilating action. Myocardial oxygen consumption was reduced by verapamil at all heart rates. The reduction was proportional to the reduction in left ventricular pressure development. Since cardiac index did not change, the efficiency of the left ventricle in performing external work was unaltered at any pacing rate.

For the whole group of patients intravenous verapamil produced no consistent improvement in myocardial metabolism. Similar numbers of patients showed adverse metabolic changes and metabolic improvement. Although verapamil reduced external work, myocardial ischaemia occurred at relatively low heart rates in some individuals as a result of reduced coronary perfusion pressure.

Clinical or echocardiographic features and data obtained at cardiac catheterisation before administration of verapamil could not be used to predict patients in whom myocardial metabolism would improve after the drug. There was no evidence that intravenous verapamil had effects on haemodynamic function and metabolism that differed in any clinically important manner in groups $A$ and $B$.

This study suggests that the negative inotropic effects of verapamil may produce beneficial effects by reducing unproductive contraction. Such effects will lower myocardial oxygen consumption, wall tension, and the outflow gradient; however, the importance of the outflow gradient in producing symptoms is disputed. ${ }^{12}$ At the same time reduced contractility will result in detrimental reductions of ejection pressure and flow and a higher filling pressure. The low flow and high filling pressures may be offset by the drug's systemic vasodilating properties, which will tend to reduce myocardial oxygen requirements further. Unfortunately, systemic vasodilatation will further reduce coronary perfusion pressure.

The only additional factor influencing myocardial energetics will be the effect of the drug on the coronary vessels. In all states coronary vascular resistance was low, which suggests that coronary vessels in patients with hypertrophic cardiomyopathy are almost maximally dilated. There is little reserve capacity for dilatation in response to increased work and the capacity of verapamil to dilate coronary vessels in these patients is therefore limited.

Whether the negative inotropic effect or systemic vasodilator effects predominate, intravenous verapamil can only lower myocardial oxygen consumption at the expense of reduced pressure development. Since verapamil has little effect on coronary vascular resistance, the only possibility of a myocardial mechanical advantage is when the reduction of myocardial oxygen consumption exceeds the 
reduction in coronary flow resulting from reduced perfusion pressure. Generally such advantage was not detectable.

Our failure to demonstrate any major or consistent improvement in haemodynamic function or myocardial metabolism after administration of intravenous verapamil may be an important consideration when deciding whether patients should receive long term oral verapamil treatment. Certainly, our findings do not demonstrate a basis on which benefits from such treatment might arise.

It is therefore important to consider carefully those reports in which verapamil is claimed to improve symptoms and exercise tolerance. There have been several open studies in which patients, who had generally been selected because they had not responded favourably to $\beta$ blockade, were found to have improved symptoms and exercise tolerance after verapamil. ${ }^{156}$ There has been only one randomised, double blind, placebo controlled trial of oral verapamil. ${ }^{13}$ The patients in this trial cannot be said to be unselected. Each patient had unacceptable symptoms or adverse effects during treatment with propranolol. Thirteen of the 19 patients in the trial had previously taken part in a short term study of the effects of intravenous verapamil, ${ }^{14}$ and presumably had demonstrated some benefit during this intervention. Despite the bias in patient selection, during a double blind comparison of placebo, propranolol, and verapamil, exercise performance during the verapamil phase was no better than during the propranolol phase and symptoms were improved almost as much by placebo as by verapamil. The treatment periods were short, however, and no adequately controlled long term trials of verapamil have been undertaken.

Thus the benefits of treatment of hypertrophic cardiomyopathy with verapamil are unproven and the evidence from this study suggests that any advantage is not clinically significant. Any potential benefits must be weighed against the danger of serious bradycardia, pulmonary oedema, and hypotension. $^{5}$

This study was supported by the Cardiac Research Fund at St Thomas' Hospital.

\section{References}

1 Kober G, Schmidt-Moritz A, Hopf R, Kaltenbach M. Long-term treatment of hypertrophic obstructive cardiomyopathy - usefulness of verapamil. Eur
Heart $\mathcal{F}$ 1983;4(suppl F):165-74.

2 Chatterjee K, Raff G, Anderson D, Parmley WW. Hypertrophic cardiomyopathy - therapy with slow channel inhibiting agents. Prog Cardiovasc Dis 1982;25:193-210.

3 Troesch M, Hirzel HO, Jenni R, Krayenbuhl HP. Reduction of septal thickness following verapamil in patients with asymmetric septal hypertrophy [Abstract]. Circulation 1979;60(suppl II):11-155.

4 Kaltenbach M, Hopf R, Kober G, Bussmann W-D, Keller M, Peterson Y. Treatment of hypertrophic obstructive cardiomyopathy with varapamil. $\mathrm{Br}$ Heart $\mathcal{F}$ 1979;42:35-42.

5 Rosing DR, Condit JR, Maron BJ, et al. Verapamil therapy: a new approach to the pharmacologic treatment of hypertrophic cardiomyopathy: III. Effects of long-term administration. Am $\mathcal{f}$ Cardiol 1981;48: 545-53.

6 Anderson DM, Raff GL, Ports TA, Bundage BH, Parmley WW, Chatterjee K. Hypertrophic obstructive cardicmyopathy: effects of acute and chronic verapamil treatment on left ventricular systolic and diastolic function. Br Heart $\mathcal{F}$ 1984;51:523-9.

7 Thompson DS, Wilmshurst P, Juul SM, et al. Pressure-derived indices of left ventricular isovolumic relaxation in patients with hypertrophic cardiomyopathy. Br Heart $\mathcal{f}$ 1983;49:259-67.

8 Thompson DS, Naqvi N, Juul SM, Coltart DJ, Jenkins BS, Webb-Peploe MM. Haemodynamic and metabolic effects of atenolol in patients with angina pectoris. Br Heart $\mathcal{F}$ 1980;43:668-79.

9 Rosing DR, Idänpään-Heikkilä U, Maron BJ, Bonow RO, Epstein SE. Use of calcium-channel blocking drugs in hypertrophic cardiomyopathy. Am $\mathcal{f}$ Cardiol 1985;55:185B-95B.

10 Bonow RO, Ostrow HG, Rosing DR, et al. Effects of verapamil on left ventricular systolic and diastolic function in patients with hypertrophic cardiomyopathy: pressure-volume analysis with a nonimaging scintillation probe. Circulation 1983;68: 1062-73.

11 Bonow RO, Frederick TM, Bacharach SL, et al. Atrial systole and left ventricular filling in hypertrophic cardiomyopathy: effect of verapamil. Am $\mathcal{F}$ Cardiol 1983;51:1386-91.

12 Goodwin JF. The frontiers of cardiomyopathy. $\mathrm{Br}$ Heart $\mathcal{F}$ 1982;48:1-18.

13 Rosing DR, Kent KM, Maron BJ, Epstein SE. Verapamil therapy: a new approach to the pharmacologic treatment of hypertrophic cardiomyopathy. II. Effects on exercise capacity and symptomatic status. Circulation 1979;60:1208-13.

14 Rosing DR, Kent KM, Borer JS, Seides SF, Maron BJ, Epstein SE. Verapamil theapy: a new approach to the pharmacologic treatment of hypertrophic cardiomyopathy. I. Hemodynamic effects. Circulation 1979;60:1201-7. 